Available online at GSC Online Press Directory

GSC Biological and Pharmaceutical Sciences

e-ISSN: 2581-3250, CODEN (USA): GBPSC2

Journal homepage: https://www.gsconlinepress.com/journals/gscbps

(RESEARCH ARTICLE)

\title{
Phytochemicals, hypoglycemic and hypolipidemic effects of methanol leaf extract of Hibiscus sabdariffa in alloxan induced diabetic rats
}

\author{
Tsado Amos Ndarubu 1, Onukogu Stella Chiamaka ${ }^{2}$, Suleiman Alfa ${ }^{3}$, Mustapha Aishatu 4, 5, Osuigwe Ekeoma \\ Chinedu 2, Dannana Luke Wenawo ${ }^{2}$, Alawode Rhamatalah Adenike 6, Lawal Bashir ${ }^{2,}{ }^{*}$ and Berinyuy \\ Bonghan Eustace ${ }^{7}$ \\ ${ }_{1}^{1}$ Department of Biological Sciences, Niger State Polytechnic Zungeru, P.M.B 001, Zungeru, Niger State. \\ ${ }^{2}$ Department of Biochemistry, Federal University of Technology Minna, P.M.B. 65, Nigeria. \\ ${ }^{3}$ Department of Biological Sciences, Federal Polytechnic Bida, Nigeria. \\ ${ }^{4}$ Department of Microbiology, Federal University of Technology Minna, P.M.B. 65, Nigeria. \\ ${ }^{5}$ Niger State Primary Health Care Development Agency. Station: PHC Tunga, Niger State Nigeria. \\ ${ }^{6}$ Forestry research institute of Nigeria-Southern Guinea Research Station, Mokwa, Niger State, Nigeria. \\ ${ }^{7}$ Faculty of medicine and biomedical sciences, University of Yaounde 1, Yaounde, Cameroon.
}

Publication history: Received on 01 September 2019; revised on 05 September 2019; accepted on 10 September 2019

Article DOI: https://doi.org/10.30574/gscbps.2019.8.3.01170

\begin{abstract}
This study investigates the phytochemicals, antidiabetic and hypolipidemic activities of Hibiscus sabdariffa methanol leaves extract in alloxan induced diabetic wistar rat by administering graded oral doses (100, $200 \mathrm{and} 400 \mathrm{mg} / \mathrm{kg}$ body weight) for 21 days. Results revealed that the methanol leaf extract of Hibiscus sabdariffa contains $51.90 \pm 3.89$ $\mathrm{mg} / 100 \mathrm{~g}$ of tannins, $102.56 \pm 6.89 \mathrm{mg} / 100 \mathrm{~g}$ of saponins, $54.78 \pm 3.89 \mathrm{mg} / 100 \mathrm{~g}$ of alkaloids, $67.45 \pm 3.87 \mathrm{mg} / 100 \mathrm{~g}$ of flavonoids and $121.54 \pm 5.67 \mathrm{mg} / 100 \mathrm{~g}$ of phenols. The extract showed dosed dependent significant $(\mathrm{p}<0.05)$ antidiabetic activity with significant improvement in body weight. The extract also resulted in significant $(\mathrm{p}<0.05$ ) reduction serum cholesterol, triglycerides. LDL-cholesterol level and increase HDL-cholesterol when compared with untreated control. In conclusion, this study demonstrates, for the first time, that Hibiscus sabdariffa is effective in inhibiting hyperglycemia and dyslipidemia in diabetes condition.
\end{abstract}

Keywords: Hibiscus sabdariffa; Phytochemicals; Hyperglycemia; Hyperlipidemia; Diabetes

\section{Introduction}

Diabetes mellitus is a metabolic disorder characterized by elevated blood glucose associated with absent or inadequate pancreatic insulin secretion, with or without concurrent impairment of insulin action [1]. The rapid global increase in the number of people with diabetes is quite alarming. More than 177 million of global population live with diabetes and this figure is likely to increase by 2030 [2]. In sub-Saharan Africa, it is estimated that 10.8 million and that this would rise to 18.7 million by 2025 [3]. In Nigeria, about 3\% of adult were reported to have DM [4]. Diabetes is a leading cause of adult blindness, amputation, stroked, renal failure and neuropathy [5]. Dislipidemia are commonly observed in hyperglycemic diabetic patient. Diabetic (NIDDM) patient with mild fasting hyperglycemia commonly present hypertriglyceridemia due to overproduction of hepatic triglyceride-rich lipoproteins, associated with decreased high-density lipoprotein (HDL) cholesterol levels [6].

Plants had been used for medicinal purposes long before recorded history. Researchers found that people in different parts of the world tended to use the same or similar plants for the same purpose [7]. Evaluation of medicinal plant

\footnotetext{
${ }^{*}$ Corresponding author

E-mail address: bashirlawal12@gmail.com
} 
used in traditional treatment of diabetes is of growing interest [8]. WHO also recommend and encourage this practice especially in country where access to conventional treatment of diabetes is inadequate [2].

Fresh or dried calyces of H. sabdariffa are used in the preparation of herbal drinks, hot and cold beverages, fermented drinks, wine, jam, jellied confectionaries, ice cream, chocolates, flavouring agents, puddings and cakes in Sudan and Nigeria, the calyces are boiled with sugar to produce a drink knownas "Karkade" or "Zoborodo" [9]. H. sabdariffa exhibited significant hypolipidemic and has antidiabetic effect [10]. The plant also showed antinociceptive and antiinflammatory effects 11. Traditionally, the plant has been used for diabetes [12]. Therefore, the present work was undertaken to explore the phytochemicals, antidiabetic and hypolipidemic potentials of $H$. sabdariffa methanol leaves extract in alloxan induced diabetic wistar rat.

\section{Material and methods}

\subsection{Sample collection}

The freshly harvested leaves of Hibiscus sabdariffa was obtained in August, 2016 from Bosso Mina, Niger state, Nigeria. Taxonomic authentication of the plant was conducted at the Department of Biology, Federal university of technology, Minna.

\subsection{Experimental Animals}

Healthy albino rats of average weight 120-150g were purchased from Animal House, School of life sciences, Federal University of Technology Minna, Nigeria. The rats were kept in clean plastic cages and maintained under standard laboratory conditions. They were allowed unrestricted access to rat pellets and water ad-libitum.

\subsection{Sample preparation and phytochemical analysis}

The leaves of Hibiscus sabdariffa was washed and air dried for 2 weeks $\left(37^{\circ} \mathrm{C}\right)$ and finally grounded using a grinder mill. Extraction of plant materials was performed by weighing $200 \mathrm{~g}$ of the powdered plant and extracted using $600 \mathrm{ml}$ of methanol. The resulting extract was concentrated in water bath. The concentrated extract was stored in airtight container prior to use. Quantitative phytochemical analysis of the plant was carried out using standard procedures as described previously [13-16].

\subsection{In vivo antidiabetic study}

Twenty-five (25) albino rats were intra-peritoneally administered a freshly prepared solution of alloxan monohydrate $(120 \mathrm{mg} / \mathrm{kg})$ to overnight fasted rats. Diabetic state was confirmed by glucose level above $200 \mathrm{mg} / \mathrm{kg} \mathrm{bw} \mathrm{[17].} \mathrm{The}$ animals were divided into 4 groups and were treated with $2 \mathrm{ml} / \mathrm{kg}$ of normal saline, $100 \mathrm{mg} / \mathrm{kg}, 200 \mathrm{mg} / \mathrm{kg}, 400$ $\mathrm{mg} / \mathrm{kg}$ bw extract and $5 \mathrm{mg} / \mathrm{kg} \mathrm{b}$. wt glibenclamide. All treatments were administered daily through oral route for 21days. Five (5) rats were also set up as normal control. The blood glucose level was checked and the weight taken on a weekly basis.

\subsection{Blood collection}

Collection of samples for lipid profile analyses was as described previously [18-19]. The animals were anasthesized with chloroform and blood was collected through cardiac puncture into a clean, dry centrifuge tubes. The blood sample was allowed to stand for 10 minutes at room temperature and then centrifuged at 1000rpm for 15 minutes to get the serum.

\subsection{Analysis of lipid profile}

Serum concentrations of lipid profile including total cholesterol, triglycerides and high density lipoprotein (HDL)-cholesterol were assay by enzymatic colorimetric methods using commercially kits according to the manufacturer's instructions [20-21]. VLDL-cholesterol was estimated as TG/5, and LDL-cholesterol was calculated using Friedewald formula [22] as follows:

$\mathrm{LDL}(\mathrm{mg} / \mathrm{dl})=\mathrm{TC}-(\mathrm{HDL}+\mathrm{VLDL})$

\subsection{Statistical analysis}


Values were analyzed using statistical package for social science (SPSS) version 16 and presented as means \pm SE of the mean. Comparisons between different groups were carried out by one way analysis of variance (ANOVA) followed by Duncan's Multiple Range Test (DMRT). The level of significance was set at $P<0.05$ [23].

\section{Results and discussion}

Plant use in treatment of disease are said to contain active compounds called phytochemicals some of which are responsible for the characteristic adours, purgensies and colour of plant while others give a particular plant its culinary medicinal or poisonous virtues [24]. Qualitative phytochemical composition of methanol leaf extract of Hibiscus sabdariffa revealed the presence of phenols, flavonoids, tannins, saponins, alkaloids, terpenes, cardiac glycoside, steroids and anthraquinone while phlobatannins was absent (Table 1). Saponin has been reported to have anti-inflamatory, cardiac depressant and hypo-cholesterol emic effect [25]. Flavonoids are the most diversified groups of phenolic compound found in plant. It biological activity include, antibacterial, anti-inflammatory, anti-allergic, protect against ulcers, vineses and antitumor effect [26]. Flavonoids are free radical scavengers, super antioxidant and potential water soluble which prevent oxidative cell, damage and have strong anti-cancer activity [27]. Alkaloid have been reported for antiplasmodial analgesic, antispasmodic, antidiabetic, anti-inflammatory properties [28]. Quantitatively, methanol leaf extract of Hibiscus sabdariffa contains $51.90 \pm 3.89 \mathrm{mg} / 100 \mathrm{~g}$ of tannins, $102.56 \pm 6.89$ $\mathrm{mg} / 100 \mathrm{~g}$ of saponins, $54.78 \pm 3.89 \mathrm{mg} / 100 \mathrm{~g}$ of alkaloids, $67.45 \pm 3.87 \mathrm{mg} / 100 \mathrm{~g}$ of flavonoids and $121.54 \pm 5.67 \mathrm{mg} / 100 \mathrm{~g}$ of phenols (Table 2). The high flavonoids and alkaloids obtained in this study could be an indication of strong antioxidative and hypoglycemic potentials of this plant. Furthermore, flavonoids of different plant origin showed a promising anti-diabetic activity, as demonstrated in diabetic animal models [29]. Previous researchers have demonstrated the hypoglycemic activity of triterpenoid glycosides [30]. Thus, the phytochemical constituents indicate that the methanol leaf extract of Hibiscus sabdariffa could have potentials to be an hypoglycemic agent. The presence of important phytochemical in this plant is an indication that this plant if properly screened could yield a drug of pharmaceutical significance. However, the absence of phlobatannins agree with early studies which also found that not all phytochemicals are present in all plant and those that present differs according to the solvent use in the extraction process [31-32].

Table 1 Qualitative phytochemical composition of methanol leaf extract of Hibiscus sabdariffa

\begin{tabular}{ll}
\hline Phytochemicals & Inference \\
\hline Phenol & + \\
Flavonoids & + \\
Tannins & + \\
Saponins & + \\
Alkaloids & + \\
Terpens & + \\
Phlobatannins & - \\
Cardiac glycoside & + \\
Anthraquinone & + \\
steroids & + \\
\hline
\end{tabular}

Table 2 Quantitative Phytochemical composition of methanol leaf extract of Hibiscus sabdariffa

\begin{tabular}{ll}
\hline Phytochemicals & Quantity \\
\hline Phenol & $121.54 \pm 5.67^{\mathrm{d}}$ \\
Flavonoids & $67.45 \pm 3.87^{\mathrm{b}}$ \\
Tannins & $51.90 \pm 3.89^{\mathrm{a}}$ \\
Saponins & $102.56 \pm 6.89^{\mathrm{c}}$ \\
Alkaloids & $54.78 \pm 3.89^{\mathrm{a}}$ \\
\hline
\end{tabular}

Data are Mean \pm SEM of triplicate determination. Values followed by different superscript alphabet were significantly different $(p<0.05)$ 
Alloxan induced diabetic untreated rats shows progressive increase in blood glucose level throughout the study period. Methanol leaf extract of Hibiscus sabdariffa exhibited dose dependent decrease blood glucose level throughout the 21 days' study period (figure 1). Methanol leaf extract of Hibiscus sabdariffa produce 68.49 \%, $73.59 \%$ and 80.47 $\%$ hypoglycemic effect at 100, 200 and $400 \mathrm{mg} / \mathrm{kgb.wt}$ respectively while the standard drug (gilbenclamide) at 5 $\mathrm{mg} / \mathrm{kg}$ bodyweight caused $81.10 \%$ hypoglycemic effect (table 3 ).

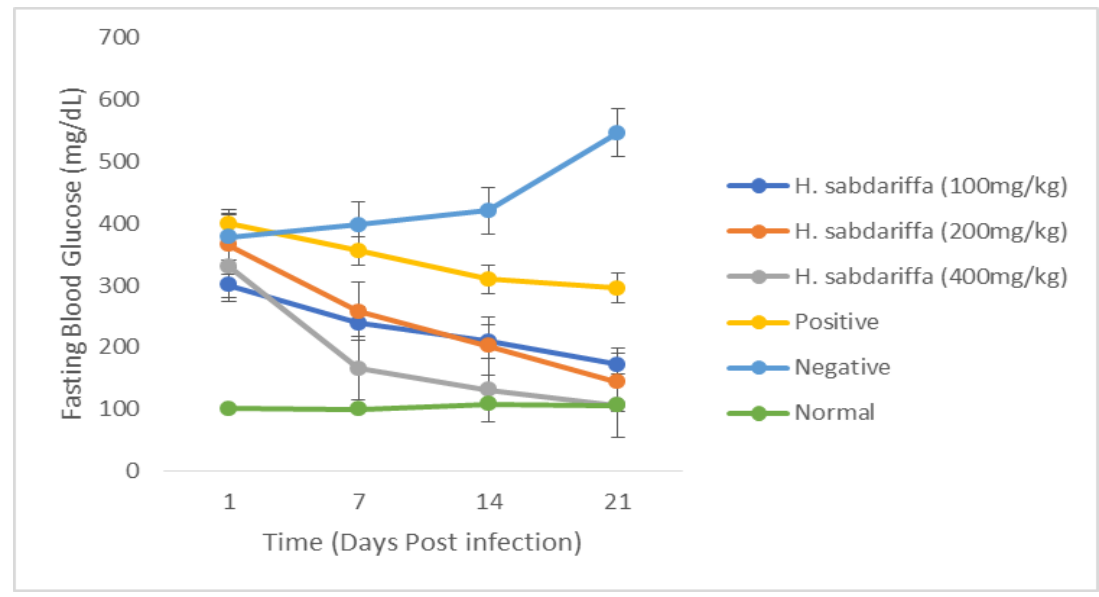

Figure 1 Effect of methanol leaf extracts of Hibiscus sabdariffa on blood glucose levels in alloxan induced diabetic rat

Table 3 Effect of methanol leaf extracts of Hibiscus sabdariffa on glucose reduction and weight gain in alloxan induced diabetic rat

\begin{tabular}{llll}
\hline & Fasting Blood Glucose (mg/dL) & Glucose Reduction (\%) & Weight gain \\
\hline H. sabdariffa $(100 \mathrm{mg} / \mathrm{kg})$ & $172.34 \pm 8.45^{\mathrm{c}}$ & 68.49 & $-5.78 \pm 0.67^{*}$ \\
H. sabdariffa $(200 \mathrm{mg} / \mathrm{kg})$ & $144.46 \pm 7.03^{\mathrm{b}}$ & 73.59 & $6.09 \pm 0.97$ \\
H. sabdariffa $(400 \mathrm{mg} / \mathrm{kg})$ & $106.82 \pm 7.65^{\mathrm{a}}$ & 80.47 & $7.70 \pm 0.87$ \\
Positive & $103.35 \pm 11.93^{\mathrm{a}}$ & 81.10 & $9.55 \pm 0.02$ \\
Negative & $547.09 \pm 23.45^{\mathrm{d}}$ & $-32.00 \pm 0.55^{*}$ \\
Normal & $106.56 \pm 6.56^{\mathrm{a}}$ & $9.42 \pm 0.87$ \\
\hline \multicolumn{2}{c}{ Data are Mean \pm SEM of triplicate determination. Values followed by different superscript were significantly different (p<0.05). }
\end{tabular}

The hypoglycemic effect of methanol leaf extract of Hibiscus sabdariffa reported in this study may be attributed to the presence of phenols, flavonoids, alkaloids, tannins and saponins that have been associated with hypoglycemic activity [33]. Leaves of Hibiscus sabdariffa have also been reported by Sachdewa \& Khemani, [12], to be hypoglycemic.

Alloxan induced diabetic untreated rats showed a progressive decrease body weight (figure 2) with final body weight loss of $32.00 \pm 0.55$. Rats treated with $100 \mathrm{mg} / \mathrm{kg}$ bw of methanol leaf extract of Hibiscus sabdariffa also exhibited progressive decrease body weight with loss of $5.78 \pm 0.67 \mathrm{~g}$. however rats treated with $200 \mathrm{and} 400 \mathrm{mg} / \mathrm{kg} \mathrm{bw}$ of the extract as well as those treated with the standard drug shows improvement in body weight with a gain of $6.09 \pm 0.97 \mathrm{~g}$, $7.70 \pm 0.87 \mathrm{~g}$ and $9.55 \pm 0.02 \mathrm{~g}$ respectively (Table 3 ). During diabetic conditions, insulin deficiency prevents the body from the utilization of glucose for energy source. Thus, the body switched to the stored fats and muscle proteins, leading to the reduction in overall body weight as observed in untreated groups. The anti-diabetic activity of Hibiscus sabdariffa methanol leaf extract is also supported by the significant weight gain of the treated animals in comparison with the untreated animals. This shows the improvement in metabolic activity of the treated animals. 


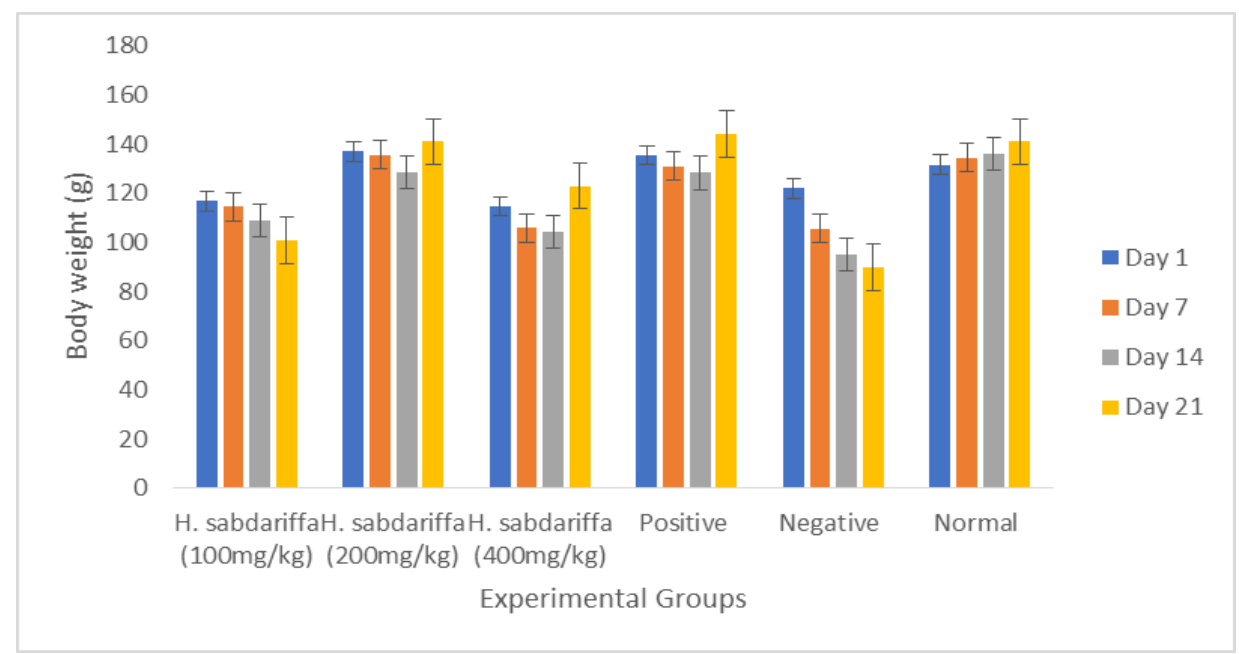

Figure 2 Effect of methanol leaf extracts of Hibiscus sabdariffa on body weight in alloxan induced diabetic rat

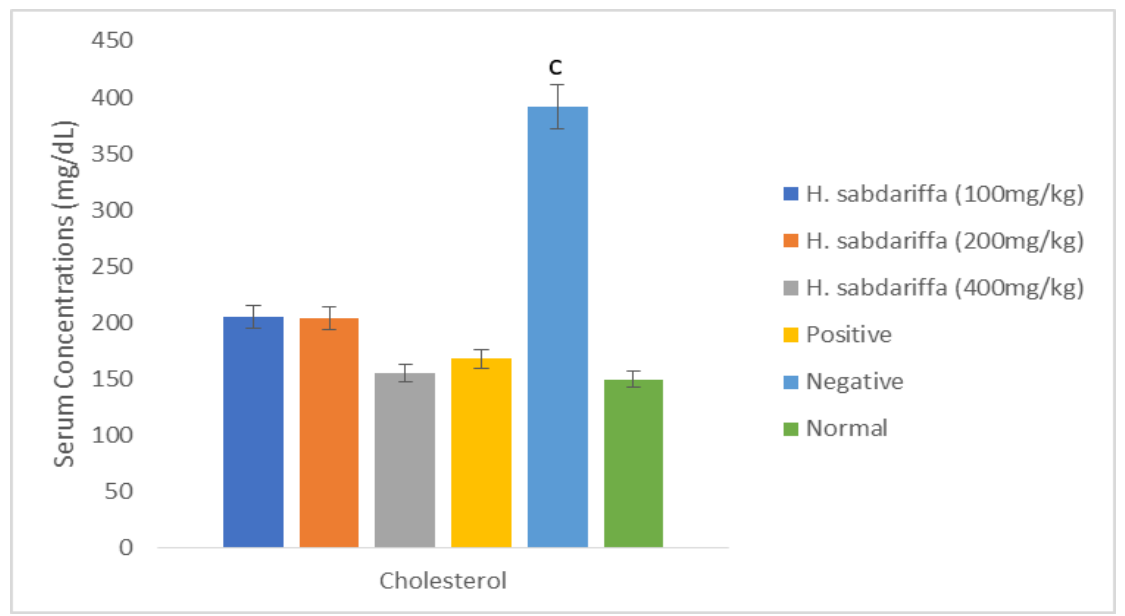

Figure 3 Effect of methanol leaf extracts of Hibiscus sabdariffa on serum cholesterol in alloxan induced diabetic rat. Bars with different superscript alphabet were significantly different $(\mathrm{p}<0.05)$

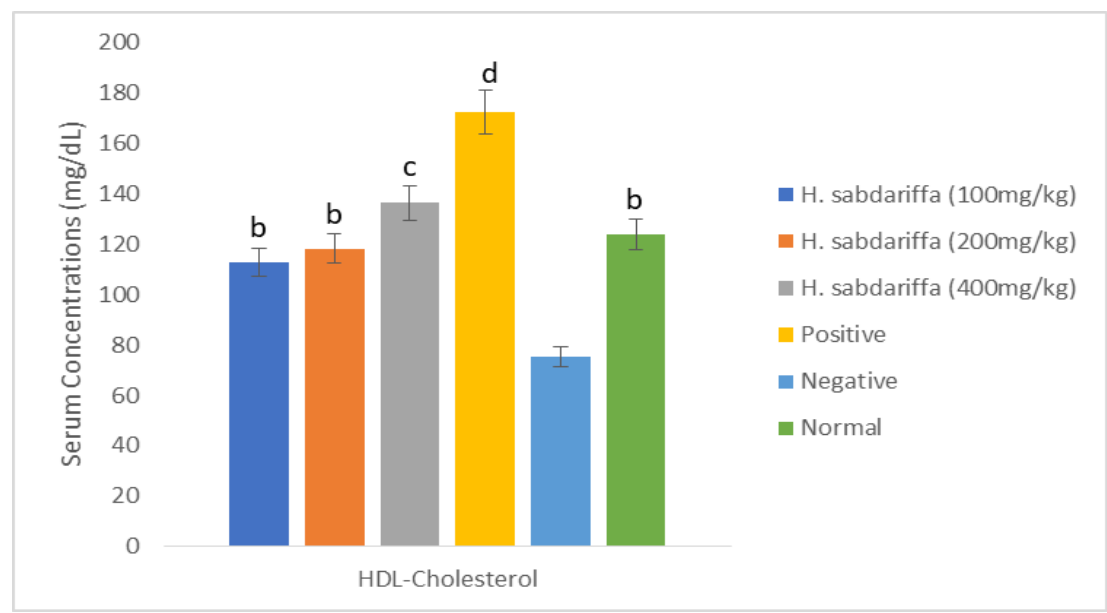

Figure 4 Effect of methanol leaf extracts of Hibiscus sabdariffa on serum triglyceride in alloxan induced diabetic rat. Bars with different superscript alphabet were significantly different $(\mathrm{p}<0.05)$ 
Since, lipid abnormalities accompanying with atherosclerosis is the major cause of cardiovascular disease in diabetes. Therefore, ideal treatment of diabetes, in addition to glycemic control, should have a favorable effect on lipid profiles. In this study, there was a significantly $(\mathrm{p}<0.05)$ increase in serum levels of total cholesterol, triglycerides, low density lipoprotein (LDL) cholesterol and decreases in high density lipoprotein (LDL) cholesterol in diabetic untreated rats when compared to the control group. Oral administration of methanol extract of leaf extract of Hibiscus sabdariffa at 100,200 and $400 \mathrm{mg} / \mathrm{kg}$ bw produced significant $(\mathrm{p}<0.05)$ reduction in total cholesterol, triacylglycerol, low density lipoprotein and also increase the high-density lipoprotein when compared with untreated control (Figure 3, 4, 5 and 6), thus indicating the hypolipidemic property of this plant.

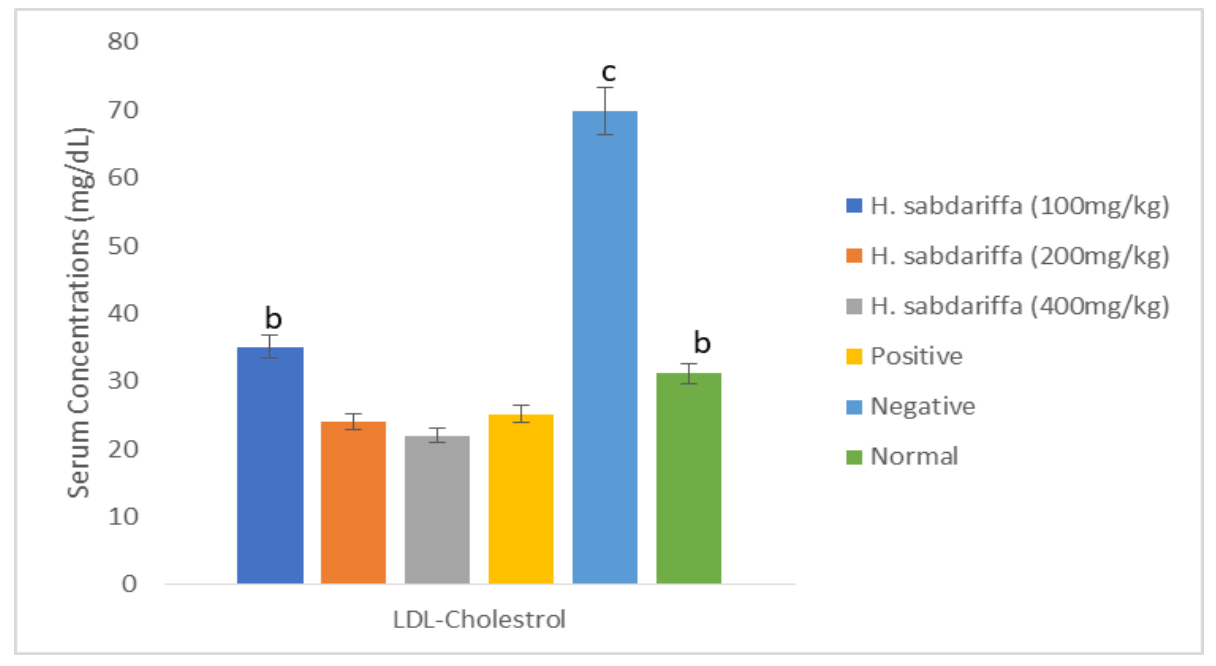

Figure 5 Effect of methanol leaf extracts of Hibiscus sabdariffa on serum LDL-cholesterol in alloxan induced diabetic rat. Bars with different superscript alphabet were significantly different $(\mathrm{p}<0.05)$

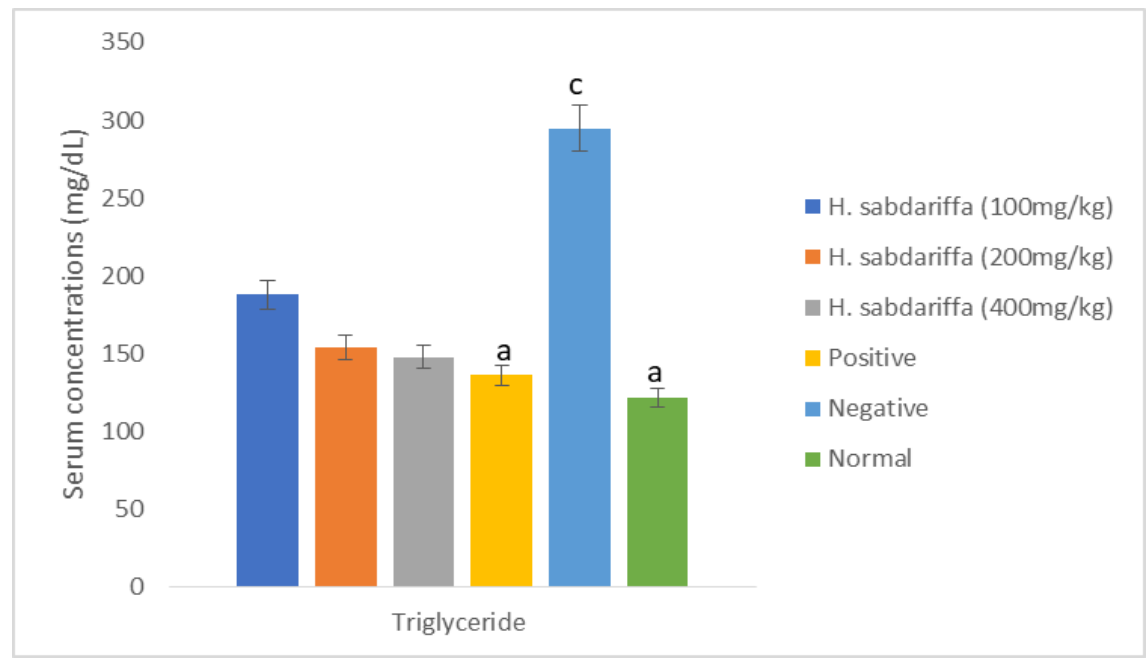

Figure 6 Effect of methanol leaf extracts of Hibiscus sabdariffa on serum triglyceride concentration in alloxan induced diabetic rat. Bars with different superscript alphabet were significantly different $(\mathrm{p}<0.05)$.

The reductions in total cholesterol concentration in serum of rats following the administration of the extract might have resulted from the presence of flavonoids, tannins and saponins that were reported to inhibit cholesterol biosynthesis in the liver [34], and the inhibition of the absorption of cholesterol via the small intestine [35]. The dose dependent reduction in triacylglycerol recorded in this study could also be attributed to the presence of alkaloids and saponins, which could result in the reduction of the absorption of dietary glucose in the gastrointestinal tract due to 'autointoxication' or "leaky gut' [35]. The dose dependent increase in serum HDL levels of rats following the administration of methanol leaf extract of Hibiscus sabdariffa suggested a possible boost of HDL-C biosynthesis in the liver promoted by the presence of flavonoids [36]. Therefore, more cholesterol would be transported from peripheral 
tissues to the liver for excretion and could be the reason for the reported trend in the serum cholesterol concentration. The observed increase and decrease in the serum HDL C and LDL-C levels respectively as compared to diabetic untreated rat, suggests a reduced risk of developing atherosclerosis following administrations of the methanol leaf extract of Hibiscus sabdariffa to diabetic rats.

\section{Conclusion}

From the result obtained from this study it can stated that the methanol leaf extract of Hibiscus sabdariffa contains important phytochemicals that has significant ameliorative effects on alloxan induced hyperglycemia and dyslipidemia.

\section{Compliance with ethical standards}

\section{Acknowledgments}

The authors would like to appreciate the technical staff of Biochemistry Department Federal University of Technology Minna, for their kind assistances.

\section{Disclosure of conflict of interest}

This work is a collaboration of all the authors. All authors read and approved the final manuscript. The authors declared no conflict of interest exist.

\section{Statement of ethical approval}

The principles governing the use of laboratory animals as laid out by the Federal University of Technology, Minna Committee on Ethics for Medical and Scientific Research and also existing internationally accepted principles for laboratory animal use and care as contained in the Canadian Council on Animal Care Guidelines and Protocol Review were duly observed.

\section{References}

[1] Owolabi OJ, Inninh SO, Anaka ON and Iyamu OA. (2014). Antidiabetic and Hypolipidemic Effects of Methanol Leaf Extract of Napoleona vogelii (Lecythidaceae). Hook and Planch on Alloxan-Induced Diabetes Mellitus in Rats Tropical Journal of Pharmaceutical Research, 13(11), 1903-1909.

[2] World Health Organisation (2000). Global Strategy on Diet Physical Activity and Health World Health Organization Geneva

[3] Haque N, Salma TR, Nurunnabi MJ, Uddin MFK, Jahangir SMZ, Islam A and Kamruzzaman M. (2011). Management of type 2 diabetes mellitus by lifestyle diet and medicinal plants Pakistan Journal of Biological Sciences, 14, 13-24.

[4] Mohammed A and Atiku MK. (2012). Antihyperglycemic and Antihyperglycemic Effect of Leaves and Stem Bark Methanol Extracts of Senna siamea in Alloxan Induced Diabetic Rats. Current Research in Cardiovascular Pharmacology, 1, 10-17.

[5] Young IS. (2005). "Lipids for psychiatrists - An overview" Journal of Psychopharmacology, 19(6), 66-75.

[6] Abbate SL and Brunzell JD. (1990). Pathophysiology ofhyperlipidaemia in diabetes mellitus. Journal of Cardiovascular Pharmacology, 9, 81-87.

[7] Bashir L, Shittu OK, Sani S, Busari MB and Adeniyi KA. (2015). African Natural Products with Potential Antitrypanosoma Properties: A Review International Journal of Biochemistry Research and Review, 7(2), 4579.

[8] Malviya N, Jain S and Malviya S. (2010). Antidiabetic potential of medicinal plants Acta Pol Pharmaceutical Drug Research, 67, 113-118.

[9] Okereke CN, Iroka FC and Chukwuma MO. (2015). Phytochemical analysis and medicinal uses of Hibiscus sabdariffa. International Journal of Herbal Medicine, 2 (6), 16-19. 
[10] Mozaffari-Khosravi H, Jalali-Khanabadi BA, Afkhami-Ardekani M and Fatehi F. (2009). Effects of sour tea (Hibiscus sabdariffa) on lipid profile and lipoproteins in patients with type II diabetes. Journal of Alternative and Complementary Medicine, 15(8), 899-903.

[11] Narender KS Kumar D and Kumar V. (2009). Antinociceptive and Anti-Inflammatory Activity of Hibiscus tiliaceus Leaves. International Journal of Pharmaceutical Product and Research, 1(1), 15-17.

[12] Sachdewa A and Khemani LD. (2003). Effect of Hibiscus rosa sinensis Linn ethanol flower extract on blood glucose and lipid profile in streptozotocin induced diabetes in rats Journal of Ethnopharmacology, 89(1), 61-66.

[13] Association of Official Analytical Chemists (2006). Official method of analysis (18th ed). Washington DC.

[14] Sofowora AE. (1993). Medicinal Plants and Traditional Medicine in Africa; John Wiley and Sons Ltd Ife Nigeria

[15] Trease GE and Evans WC. (1989). Pharmacognosy 11th ed BrailliarTridel and Macmillian Publishers London 48-65.

[16] Tsado NA, Lawal B, Santali ES, Mohammed AS, Balarabe MM, Ibrahim HA and George JJ. (2015). Phytochemicals and Acute Toxicity Profile of Aqueous and Methanolic Extracts of Crateva adansonii Leaves in Swiss Albino Rats. Asian Journal of Biochemistry Asian Journal of Biochemistry, 10 (4), 173-179.

[17] Etuk EU, Bello SO and Isezuo SA. (2010). Ethnobotanical Survey of Medicinal Plants used for the Treatment of Diabetes Mellitus in the North Western Region of Nigeria. Asian Journal of Experimental Biology and Sciences, 3(1), 55-59.

[18] Bashir L, Shittu OK, Busari MB, Sani S and Aisha MI. (2015). Safety Evaluation of Giant African land Snails (Archachatina marginata). Haemolymph on Hematological and Biochemical Parameters of Albino Rats. Journal of Advances in medical and Pharmaceutical Sciences, 3(3), 122-130.

[19] Yusuf AA, Lawal B, Yusuf MA, Omonije YO, Adejoke AA, Raji FH and Wenawo DL. (2018). Free Radical Scavenging Antimicrobial Activities and Effect of Sub-Acute Exposure to Nigerian Xylopia Aethiopica Seed Extract On Liver and Kidney Functional Indices of Albino Rat. Iranian journal of toxicology, 12 (3), 51-58.

[20] Stern S. (1987). High density lipoprotein subfractions and coronary risk factors in normal men Arteriosclerosis Thrombosis and Vascular Biology, 7(4), 341-346.

[21] Assmann G, Schriewer H, Schopohl B and Funke H. (1979). Investigation of the Specificity of the HDLcholesterol test In Lipoproteins and coronary heart disease new aspects of the diagnosis and therapy of disorders of lipid metabolism. International Symposium Vienna, 3(4), 43-45.

[22] Friedewald T, Levy I and Fredrickso S. (1972). Estimation of the concentration of low-density lipoprotein cholesterol in plasma without use of the preparative ultracentrifuge Clinical Chemistry, 1 (8), 499-502.

[23] Adamu SO and Johnson TL. (1997). Statistics for Beginners Book 1 SAAL Publications Ibadan Nigeria.

[24] Evans WC. (2002). Trease and Evans pharmalognosy (15th edition). WB Saunders Company LTD Condon 191393.

[25] Trease GE and Evans WC. (1989). Pharmacognosy 11th ed BrailliarTridel and Macmillian Publishers London 48-65.

[26] Okwu DE and Okwu ME. (2004). Chemical composition of SpondiasmombinLinnPlant parts. Journal of Sustainable Agriculture and Environment, 6 (2), 140-147.

[27] Lawal B, Shittu OK, Oibiokpa FI Berinyuy EB and Muhammed H. (2016). African natural products with potential antioxidants and hepatoprotectives properties: a review Clinical Phytoscience, 2 (23), 1-66.

[28] Jigam AA, Mahmood F and Lawal B. (2017). Protective effects of crude and alkaloidal extracts of Tamarindus indica against acute inflammation and nociception in rats Journal of Acute Disease, 6(2), 78-81.

[29] Kim HY, Moon BH, Lee HJ and Choi DH. (2004). Flavonoids glycosides from the leaves of Eucommiaulmoides with glycation inhibitory activity Journal of Ethnopharmacology 93, 227-230.

[30] Kako M, Miura T, Nishiyama Y, Ichimaru M, Mariyasu M and Kato A. (1997). Hypoglycemic activity of some Triterpenoid Glycosides. Journal of Natural Products, 60, 604-605.

[31] Tsado AN, Bashir L, Mohammed SS, Famous IO, Yahaya AM, Shu'aibu M and Caleb T. (2015). Phytochemical Composition and Antimalarial Activity of Methanol Leaf Extract of Crateva adansonii in Plasmodium berghei Infected Mice British Biotechnology Journal, 6(4), 165-173. 
[32] Lawal B, Ossai PC, Shittu OK and Abubakar AN. (2014). Evaluation of Phytochemicals Proximate Minerals and Anti-Nutritional Compositions of Yam Peel Maize Chaff and Bean Coat International Journal of Applied Biological Research, 6(2), 01-17.

[33] Chang-Yong Y, Jing W, Yuan Z, Xing J and Zhen-Guo X. (2010). Anti-diabetic effects of Panax notoginseng saponins and its major anti-hyperglycemic components Journal of Ethnopharmacology, 130, 231-236.

[34] Sinclair D, Davies MJ, Magliola C and Pivetti MV. (2001). Red wine and health benefits Journal of Science and Food Agriculture, 88, 206-213.

[35] Evers BM. (2008). Small intestine In: Townsend CM Beauchamp RD Evers B M, Mattox K L, eds Sabiston Textbook of Surgery 18th ed St Louis Mo: WB Saunders; chap 48

[36] Renaud S, Gueguen R, Siest G and Salamon R. (1999). Wine beer and mortality in middle-aged men from eastern France. Archive of Internal Medicine, 159, 1885-1870.

\section{How to cite this article}

Tsado NA, Onukogu SC, Suleiman A, Mustapha A, Osuigwe EC, Dannana LW, Alawode AR, Lawal B and Berinyuy BE. (2019). Phytochemicals, hypoglycemic and hypolipidemic effects of methanol leaf extract of Hibiscus sabdariffa in alloxan induced diabetic rats. GSC Biological and Pharmaceutical Sciences, 8(3), 70-78. 